Alison S. Carr MB BS FRCA, Jerrold Lerman MD FRCPC, Mary Cunliffe MB FFARCS, M. Elizabeth McLeod MD FRCPC, Beverley A. Britt MD FRCPC*

\title{
Incidence of malignant hyperthermia reactions in 2,214 patients under- going muscle biopsy
}

Dans le but de déterminer lincidence des réactions dhyper-

To determine the incidence of malignant hyperthermia (MH) reactions after trigger-free anaesthesia in a large population of MH-susceptible (MHS) patients, the charts of 2,214 patients who underwent elective muscle biopsy for malignant hyperthermia were reviewed. Either general or regional anaesthesia with non-triggering drugs was used. For general anaesthesia, the trachea was intubated in the absence of muscle relaxants. The halothane/caffeine contracture test was performed on the biopsied muscle. Suspected MH reactions were identified according to their site of occurrence (in the operating room, recovery room or ward). Ninety-seven percent of patients received a general anaesthetic; $3 \%$ received a regional anaesthetic or field block. Of the 2214 patients whose muscles were biopsied, 1082 patients were biopsy-positive for $M H$. Five patients in whom $M H$ reactions were diagnosed in the recovery room were all subsequently proved to be biopsy-positive for $M H$. Four of the five received intravenous dantrolene as part of their therapy; the fifth received only symptomatic therapy as parenteral dantrolene was not commercially available. All patients recovered completely from their reactions. We conclude that the incidence of $M H$ reactions in biopsy-positive patients who receive a trigger-free anaesthetic for minor surgery is small $10.46 \%$, $(0.15-1.07 \%, 95 \%$ CI)). These reactions occur in the immediate postoperative period.

\section{Key words \\ ANAESTHESIA: general, regional; \\ COMPLICATIONS: myopathy; \\ HYPERTHERMIA: malignant.}

From the Department of Anaesthesia and The Research Institute, The Hospital for Sick Children and the Departments of Anaesthesia and Pharmacology,* The Toronto General Division, University of Toronto, Toronto, Ontario.

Presented in part at the annual meeting of the International Anesthesia Research Society, Orlando, Florida, March 1987. Address correspondence to: Dr. J. Lerman, Department of Anaesthesia, The Hospital for Sick Children, 555 University Avenue, Toronto, Ontario, M5G 1 X8. Accepted for publication 9th December, 1994. thermie maligne (HM) après une anesthésie libre d'agent déclenchant dans une population importante de patients susceptibles, les dossiers de 2214 patients soumis à une biopsie musculaire en chirurgie réglée ont été révisés. Une anesthésie générale ou régionale avait été administrée. Pour la générale, la trachée avait été intubée sans myorelaxants. Le test de contracture à lhalothane/caféine était réalisé sur léchantillon de muscle prélevé. Les réactions suspectes d'HM étaient identifíées selon l'endroit de leur apparition (salle d'opération, salle de réveil ou étage) Quatre-vingt-dix-sept pour cent des biopsies ont été effectuées sous anesthésie générale et $3 \%$ sous régionale ou infiltration locale. Des 2214 patients biopsiés, 1082 étaient positifs pour l'HM. Chez les cinq patients dont le diagnostic avait été fait en salle de réveil, tous avaient une biopsie positive. Quatre de ceux-ci ont été traités au dantrolène intraveineux; comme Le dantrolène n'était pas encore sur le marché pour le cinquième, un traitement purement symptomatique a été administré. La récupération a été totale pour tous les patients. Nous concluons que lincidence des réactions d'HM chez les porteurs d'une biopsie positive est minime lorsquils subissent une biopsie musculaire avec des anesthésiques libres d'agent déclenchant $(0,46 \%$, $(0,15-1,07 \%, I C$ 95\%)). Ces réactions surviennent à la période pastopératoire immédiate.

During the past 30 years, the mortality from malignant hyperthermia (MH) has decreased from more than $80 \%$ to less than $10 \%$. This decrease has been attributed to several factors, including the widespread availability of intravenous dantrolene ${ }^{1}$ and an increased awareness and understanding of malignant hyperthermia by physicians. ${ }^{2}$ In the mid-1970s, the only definitive and reliable treatment for $\mathrm{MH}$ reactions, a parenteral formulation of dantrolene sodium, became available. The widespread availability of $i v$ dantrolene sodium, ${ }^{3}$ recognized as one of the most important advances in the management of $\mathrm{MH}$ reactions, has decreased both the severity of and the mortality from acute $\mathrm{MH}$ reactions. ${ }^{4}$ Recognition of the signs and symptoms of $\mathrm{MH}$ reactions has also led to early institution of treatment. This has further decreased the mortality from MH by arresting the reaction before ir- 
TABLE I Demographic data

\begin{tabular}{lllll}
\hline Biopsy results & $M H^{+}$ & $K-M H$ & $M H^{-}$ & Total \\
\hline Number of patients & 808 & 274 & 1132 & 2214 \\
Age (yr)* & $32.5 \pm 14.3$ & $31.4 \pm 13.2$ & $32.5 \pm 16.1$ & \\
Anaesthetic technique & & & & \\
- General & 783 & 267 & 1103 & 2153 \\
- Regional or field block & 25 & 7 & 29 & 61 \\
\hline *Data are means \pm SD. & \multicolumn{4}{l}{} \\
MH $^{+}$consists of those patients with the following contracture test results: C-MH, CK-MH, H-MH, HC-MH, \\
HCK-MH and HK-MH as defined in Table II. \\
MH- includes biopsy-negative patients and controls as defined in Table II.
\end{tabular}

reversible end-organ damage has occurred. Identification of the drugs that trigger $\mathrm{MH}$ reactions has also enabled anaesthetists to provide "safe" anaesthesia (i.e., anaesthesia without drugs that trigger $\mathrm{MH}$ reactions) for known malignant hyperthermia-susceptible (MHS) patients. This has decreased the incidence of but not eliminated MH reactions in the perioperative period.

Interestingly, several groups have reported a zero incidence of $\mathrm{MH}$ reactions after trigger-free anaesthesia in susceptible patients. ${ }^{5-10}$ Although it is tempting to generalize their findings to the entire population of MHS patients, we recommend caution in this regard as these studies lacked sufficient power, ie., the sample sizes were too small, to estimate the incidence of reactions in the entire population of susceptible patients reliably. In order to determine the incidence of $\mathrm{MH}$ reactions in a large cohort of biopsy-positive patients who received a triggerfree anaesthetic, we reviewed the charts of 2,214 patients who underwent elective muscle biopsies for MHS in Toronto between 1971 and 1993.

\section{Methods}

The medical records of 2,214 patients who had consented to an elective muscle biopsy were reviewed. In the majority of patients, the indications for muscle biopsy were a previous MH reaction; a family history of an MH reaction, positive muscle biopsy or sign/symptoms of $\mathrm{MH}$; or undiagnosed muscle cramps. In a majority of patients (controls), a muscle biopsy was performed during anaesthesia for an unrelated surgical procedure (usually orthopaedic) that used the same incision. These patients (controls) were without a history of MH susceptibility or myopathy but consented for a muscle biopsy.

All patients were admitted on the night before surgery and a preoperative assessment was completed. An intravenous infusion of lactated Ringer's solution was commenced. The patients were fasted from midnight.

A benzodiazepine (diazepam $0.2 \mathrm{mg} \cdot \mathrm{kg}^{-1}$ or lorazepam $0.03 \mathrm{mg} \cdot \mathrm{kg}^{-1}$ ) was administered po on the evening before surgery and was repeated two hours before surgery. Morphine $0.1 \mathrm{mg} \cdot \mathrm{kg}^{-1}$ or Pantopon ${ }^{\circledR} 0.2$ $\mathrm{mg} \cdot \mathrm{kg}^{-1}$ was administered im one hour before surgery.

On arrival in the operating room, all patients were monitored with an ECG, an automated blood pressure cuff, an axillary temperature probe and a pulse oximeter. End-tidal carbon dioxide tension was monitored routinely after 1987.

A general or regional anaesthetic, or a field-block was used according to the anaesthetist's preference (Table I). For patients who received general anaesthesia, anaesthesia was induced with nitrous oxide and oxygen by mask (delivered via a "vapour-free" anaesthetic machine), Innovar ${ }^{\circledR} 1 \mathrm{ml}$ per $15 \mathrm{~kg}$ and diazepam or midazolam $i v$. After the trachea was intubated without the aid of muscle relaxants, the lungs were hyperventilated $\left(\mathrm{PaCO}_{2} 30-35\right.$ $\mathrm{mmHg}$ ) using a Ventimeter ${ }^{\circledR}$ ventilator and either a new Bain or circle circuit with fresh soda lime. Anaesthesia was maintained with nitrous oxide and oxygen and repeated doses of fentanyl $i v$ as required.

After induction of anaesthesia, nasal and rectal temperature probes were inserted. All patients were actively cooled using a servo-controlled cooling blanket. The temperature in the operating room was maintained at $17^{\circ} \mathrm{C}$. For patients who were scheduled for regional anaesthesia, an epidural or spinal anaesthetic was administered using tetracaine, mepivacaine or lidocaine. For field blocks, lidocaine was used. Muscle was biopsied from the vastus lateralis, rectus femoris or since 1988 , the gracilis muscle. The biopsy was immediately mounted between two clamps and immersed in carbogenated Kreb's solution. A small biopsy was also frozen in liquid carbon dioxide and then analyzed as described previously. ${ }^{3}$

At the completion of surgery, all anaesthetic drugs were discontinued and $100 \%$ oxygen was administered. Upon arrival in the recovery room, axillary and nasal temperature sites, heart rate, respiratory rate and blood pressure were monitored for at least four to six hours. If the vital signs were stable, the patient was then transferred to the step-down unit for at least $24 \mathrm{hr}$. 
TABLE II Muscle biopsy results

\begin{tabular}{|c|c|c|c|}
\hline Category & Diagnosis & In vitro stimulus & $\begin{array}{l}\text { Number of } \\
\text { patients }\end{array}$ \\
\hline \multirow{8}{*}{$\mathrm{MH}^{+}$} & HCK-MH & Halothane alone and caffeine alone and combination* & 381 \\
\hline & HC-MH & Halothane alone and caffeine alone & 49 \\
\hline & HK-MH & Halothane and combination ${ }^{*}$ & 53 \\
\hline & CK-MH & Caffeine and combination* & 200 \\
\hline & H-MH & Halothane alone & 41 \\
\hline & C-MH & Caffeine alone & 84 \\
\hline & K-MH & Combination* & 274 \\
\hline & & Total & 1082 \\
\hline \multirow[t]{4}{*}{$\mathrm{MH}^{-}$} & Non-susceptible & Negative biopsy in a patient who was suspected MHS & 936 \\
\hline & controls & Negative biopsy in a patient who was not suspected MHS & 196 \\
\hline & & Total & $\underline{1132}$ \\
\hline & & Grand total & 2214 \\
\hline
\end{tabular}

*Combination of halothane plus caffeine.

If the vital signs were stable, the patient was then transferred to the step-down unit for at least $24 \mathrm{hr}$.

Dantrolene was not administered unless an $\mathrm{MH}$ reaction was suspected. The halothane/caffeine contracture tests were conducted using criteria that were published previously. "The laboratory conditions for the in vitro contracture response were modified in 1987; the response of $0.25 \mathrm{mM}$ caffeine was replaced by $0.50 \mathrm{mM}$ for the caffeine response test and $1 \%$ and $2 \%$ halothane were replaced by $3 \%$ halothane.

Patients whose contracture test results were positive, were grouped according to their diagnoses: HCK-MH, HC-MH, HK-MH, CK-MH, H-MH, C-MH and KMH as defined in Table II.

The genealogy of the patients (except control patients) was identified.

Suspected perioperative $\mathrm{MH}$ reactions were diagnosed by the attending staff who were unaware of the muscle biopsy results. The diagnosis was based on clinical signs and laboratory data where available. Post hoc, the malignant hyperthermia clinical grading scale (MH rank from 1 to 6) ${ }^{12}$ of increasing likelihood that the suspected event was an $\mathrm{MH}$ reaction was applied to all presumed MH reactions. The scale depends, in part, on biochemical indices including arterial $\mathrm{PCO}_{2}$, serum creatine phosphokinase and myoglobin. ${ }^{12}$

Ages were compared using the unpaired Student's $t$ test. The incidences of $\mathrm{MH}$ reactions (with $95 \%$ confidence intervals $(95 \% \mathrm{CI}))^{13}$ among the muscle biopsy groups were compared using Chi-square analysis and Fisher's exact test. Statistical significance was accepted as $P<0.05$.

\section{Results}

The age range of the 2,214 patients in whom muscle

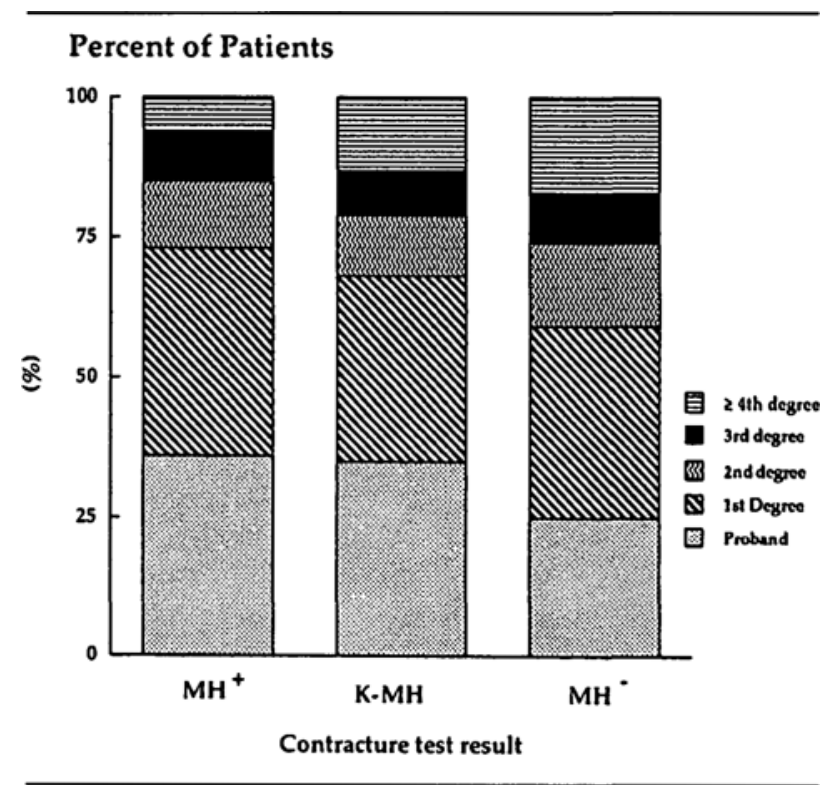

FIGURE The genealogy (as related to the proband) of patients who underwent muscle biopsy for malignant hyperthermia susceptibility according to their contracture test results. Biopsy-positive results (Table II for criteria) are denoted as $\mathrm{MH}^{+}, \mathrm{K}$-type as $\mathrm{K}-\mathrm{MH}$ and biopsy negative as $\mathrm{MH}^{-}$. Positive muscle biopsies were present in relatives of all orders, even fourth degree relatives and beyond.

was biopsied was 1-95 yr. The mean ages of the biopsy positive and negative patients were similar (Table I). General anaesthesia was administered to $97 \%$ of patients and regional anaesthesia or a field block to $3 \%$.

Of the patients who were biopsied, 1,082 were biopsypositive for MH. The numbers of patients within each subcategory of contracture results are listed in Table II.

The genealogy of 1929 of the patients is summarized in the Figure according to the contracture test results. 
TABLE III Suspected MH reactions in patients undergoing muscle biopsy

\begin{tabular}{|c|c|c|c|c|c|}
\hline Demographic data & Case 1 & Case 2 & Case 3 & Case 4 & Case 5 \\
\hline Age (yr) & 12 & 24 & 3 & 15 & 26 \\
\hline Sex & Female & Female & Female & Male & Male \\
\hline Biopsy date (yr) & 1977 & 1977 & 1979 & 1981 & 1984 \\
\hline Contracture test result & K-MH & $\mathrm{K} \cdot \mathrm{MH}$ & CK-MH & $\mathbf{K} \cdot \mathbf{M H}$ & HCK-MH \\
\hline Relation to proband & Daughter & Sister & Proband & Proband & Proband \\
\hline \multicolumn{6}{|l|}{ Characteristics of the $M H$ reaction } \\
\hline Rigidity & Present & Absent & Absent & Absent & Absent \\
\hline Hyperthermia & $38.8^{\circ} \mathrm{C}$ & $38.1^{\circ} \mathrm{C}^{*}$ & $39.1^{\circ} \mathrm{C}^{*}$ & $39^{\circ} \mathrm{C}^{*}$ & $38.8^{\circ} \mathrm{C}^{*}$ \\
\hline Tachycardia (heart rate, bpm) & $100 / \mathrm{min}$ & $120 / \mathrm{min}$ & $160 / \mathrm{min}$ & $160 / \mathrm{min}$ & $100 / \mathrm{min}$ \\
\hline PVC & & & Occasional & & \\
\hline Hyper-/hypotension & $90 / 50$ & $140 \dagger$ & $140 \dagger$ & $130 \dagger$ & $180 \dagger$ \\
\hline Tachypnoea (respiratory rate, breaths per minute) & & 25 & 40 & 24 & 25 \\
\hline Cyanosis & & & Present & & \\
\hline Drowsiness & Marked & & & & Marked \\
\hline Arterial blood gas analysis & & & $\begin{array}{l}\mathrm{pH}=7.36 \\
\mathrm{PCO}_{2}=59 \mathrm{mmHg} \\
\mathrm{PO}_{2}=64 \mathrm{mmHg} \\
\mathrm{HCO}_{3}=22\end{array}$ & & \\
\hline CPK (IU/l) & $994 \ddagger$ & & & & 79 \\
\hline
\end{tabular}

* Rectal temperature.

†Only systolic blood pressure was reconded.

$\ddagger 25 \mathrm{hr}$ post-biopsy.

The data are based on 798 biopsy-positive $\left(\mathrm{MH}^{+}\right)$patients, 269 biopsy-positive patients of the K-MH sub-type (K-MH) and 862 biopsy-negative $\left(\mathrm{MH}^{-}\right)$patients. The genealogy of the remaining patients was not included because either the information was incomplete or the patients were controls.

Five patients $(0.46 \%)$ developed signs that were suggestive of $\mathrm{MH}$ reactions. All five reactions occurred in the recovery room after general anaesthesia. These five patients were subsequently proved to be biopsy-positive for MH; HCK-MH $(n=1)$, C-MH $(n=1)$ and KMH $(n=3)$. Four of the five patients had had general anaesthesia before: two had developed hyperthermic reactions, another had developed muscle rigidity after succinylcholine without a concomitant increase in temperature and the fourth had three previous uneventful anaesthetics, but had a family history of $\mathrm{MH}$ reactions and a positive muscle biopsy in a relative. Four of the five patients were treated with dantrolene $\dot{i}$, two of these also received propranolol, chlorpromazine and procainamide. The fifth was treated with vigorous cooling and procainamide since dantrolene $i v$ was not available for clinical use at that time. All five patients shivered before the onset of their reactions. Details of the MH reactions are presented in Table III. All five patients survived without additional complications. When the five suspected reactions were ranked using the malignant hyperthermia clinical grading scale, ${ }^{12}$ they scored values of $\leq 4$. This implies that the events were a "somewhat more than likely" MH event.

The incidence of $\mathrm{MH}$ reactions in the biopsy-positive patients $5 / 1082(0.46 \%)$ was similar to the zero incidence in the 1,132 biopsy-negative patients $(P<0.065)$. However, the incidence of reactions in patients with a K-MH contracture result, $3 / 274$, was greater than the incidence in the biopsy-negative patients $(P<0.007)$.

\section{Discussion}

In this retrospective review, only five of 1082 patients or $0.46 \%(0.15-1.07 \%, 95 \% \mathrm{CI})$ who were biopsy-positive for $\mathrm{MH}$, developed clinical signs of acute $\mathrm{MH}$ reactions after trigger-free anaesthesia for a muscle biopsy. In contrast to our results, there are several reports of a zero incidence of $\mathrm{MH}$ reactions in susceptible patients. ${ }^{5-10} \mathrm{Be}-$ cause the sample sizes in those studies were small, we pooled the patient numbers giving a total of 178 biopsypositive patients (194 including patients with equivocal biopsy results). If we assume that our incidence of reactions $(0.46 \%)$ is the true incidence, then the probability that 178 susceptible patients will experience no reactions is $44 \%$ ( $41 \%$ if the patients with equivocal biopsy results are included). ${ }^{14}$ The probability is even greater if the actual sample sizes for the individual studies, rather than pooled sample, are used. Thus, it is not surprising that 
no reactions were observed in the smaller published studies.

The upper $95 \%$ confidence limit that is compatible with a zero incidence of $\mathrm{MH}$ reactions in 178 (or 194 including patients with equivocal biopsy results) is $1.7 \%$ (1.6\% including patients with equivocal biopsy results). ${ }^{14}$ These incidences are more than $50 \%$ greater than the upper $95 \%$ $\mathrm{CI}$ of $\mathrm{MH}$ reactions in this study. This difference in the upper confidence interval can be explained by the sixfold difference in the sample size between our study and the pooled studies.

The MH reactions reported in this study are evidence that $\mathrm{MH}$ reactions can occur in susceptible patients even after trigger-free anaesthesia. ${ }^{15}$ When all of the precautions for MHS are combined (identification of MH susceptibility, use of "clean" or "volatile agent-free" anaesthetic equipment and the avoidance of triggers), the incidence of $\mathrm{MH}$ reactions in the perioperative period is small but not zero. Appropriate monitoring, dantrolene and the suspicion that an acute $\mathrm{MH}$ reaction may occur at any time, must always be considered in these subjects.

If the standard measures mentioned above cannot prevent $\mathrm{MH}$ reactions, then it might seem reasonable to recommend prophylactic dantrolene for all susceptible patients. However, we do not support this strategy for the following reasons. First, the routine use of prophylactic medications is unjustifiable when $99.5 \%$ of the affected population will not have direct need of it. Second, side effects and complications from dantrolene $i v$ are potentially serious. Dantrolene may increase morbidity when it is administered to a very large population of patients. Third, the effectiveness of prophylactic dantrolene in preventing MH reactions has yet to be established. Fourth, previous studies have demonstrated that acute $\mathrm{MH}$ reactions can be managed effectively with dantrolene iv provided the diagnosis is made in a timely manner. Fifth, the cost-benefit ratio of prophylactic dantrolene is unproven and would most likely be substantial. On the basis of these arguments, routine prophylactic dantrolene cannot be justified. One exception, however, would be those centres in which the incidence of MH reactions is greater than that reported here. In such cases, prophylactic dantrolene might be justified.

Although the five reactions that occurred in the recovery room were diagnosed as $\mathrm{MH}$ reactions, other diagnoses were possible. Shivering may cause trachycardia (present in three of the five patients) and a small increase in blood pressure (present in four of the five patients). All five patients shivered before their reactions were diagnosed and this might have obscured the signs of an MH reaction. Hypoventilation may explain in part, the increase in the $\mathrm{PCO}_{2}$ observed in at least one patient.
The CPK blood levels when measured were normal. It is possible, but unlikely in our opinion, that these events were not MH reactions.

When we applied the clinical grading scale for $\mathrm{MH}^{12}$ to score the events in this study, the MH ranks were consistently $\leq 4$ or, suggesting a "somewhat greater than likely" chance that these were $\mathrm{MH}$ reactions. Although we may have expected a greater rank and therefore a greater likelihood that these were indeed during MH reactions, the maximum scores were limited, in part, by the retrospective nature of this study and the limited data available. The malignant hyperthermia clinical grading scale attributes its score to both clinical and biochemical indices; but, in the present study few biochemical data were available. Consequently, the clinical grading scale and therefore the MH rank of these reactions were based on incomplete data and most likely underestimated the true score. On the basis of the available data and the scores obtained, it is impossible to conclude whether these "events" were indeed MH reactions.

Before 1987, the halothane/caffeine contracture test included the responses to 1 and $2 \%$ halothane whereas after $1987,{ }^{16}$ it included only the responses to $3 \%$ halothane. This increased concentration of halothane would be expected to decrease the number of false-negative biopsies. However, to date, none of the patients who was biopsied before 1987, has returned for a repeat muscle biopsy to ascertain whether his/her biopsy category has changed. We presume that some of the patients who were biopsied before 1987 and who were biopsy-negative may actually be MH susceptible. However, this presumption remains speculative.

In the present study, all five suspected MH reactions occurred in the recovery room after trigger-free anaesthesia. This is consistent with one published report of three similar cases. ${ }^{15}$ Reactions that occur in the recovery room are thought to be less severe than those that occur during general anaesthesia. ${ }^{11,17}$ Nonetheless, they usually present with findings that are typical of an $\mathrm{MH}$ reaction including tachycardia, multifocal ventricular arrhythmias, an increase in axillary temperature, and blood/gas abnormalities including hypercapnia, a base deficit and a lowered oxygen tension. Two additional signs have been reported during $\mathrm{MH}$ reactions in the recovery room; excessive drowsiness and agitation. All four reactions that were treated with dantrolene in the recovery room in this study terminated rapidly and completely. ${ }^{17}$

Although the cluster of presumed $\mathrm{MH}$ reactions that occurred in the recovery room might be considered exceptional, there are several substantive reasons to expect MH reactions to occur there. First, the stress of arousal and pain, or shivering may trigger an $\mathrm{MH}$ reaction. All five patients who experienced these reactions shivered be- 
fore the reactions began. Although none of the five patients was hypothermic on arrival in the recovery room (ambient temperature of $19.5^{\circ} \mathrm{C}$ ), it is possible that they shivered because they had been actively cooled in the operating theatre. Second, trace concentrations of potent volatile anaesthetics in the recovery room may trigger a reaction. Third, the protective effects of certain anaesthetic drugs such as thiopentone, would have dissipated by the time the patient arrived in the recovery room. ${ }^{18}$ Individually or combined, these three reasons provide insight into the genesis of $\mathrm{MH}$ reactions in the recovery room.

Concerns about the importance of shivering in the genesis of MH reactions has led us to modify our strategy for managing the temperature of susceptible patients in the operating room. Rather than actively cooling them, we have begun to actively warm suspectible patients in the operating room. Several modalities have been used including a warming blanket, a heated humidifier, and increasing the ambient temperature. Although $\mathrm{MH}$ reactions have not occurred after a muscle biopsy in susceptible patients since this change was implemented, a cause and effect relationship has not been established. Further studies are required to identify the causal triggers that are responsible for $\mathrm{MH}$ reactions in the recovery room.

We conclude that $\mathrm{MH}$ reactions can occur after triggerfree anaesthesia for muscle biopsy in susceptible patients. If all five events that occurred in the recovery room were $\mathrm{MH}$ reactions, then the incidence of $\mathrm{MH}$ reactions after trigger-free anaesthesia in biopsy-positive patients is small, $0.46 \%(0.15-1.07 \%, 95 \% \mathrm{CI})$.

\section{References}

1 Britt BA. Dantrolene - an update. In: Britt BA (Ed.). Malignant Hyperthermia. Boston: Martinus Nijhoff Publishing 1987: 325-67.

2 Prather Strazis $K$, Fox $A W$. Malignant hyperthermia: a review of published cases. Anesth Analg 1993; 77: 297-304.

3 Britt BA. Malignant hyperthermia: a review. In: Milton AS (Ed.). Handbook of Experimental Pharmacology. Berlin: Springer-Verlag 1982: 547-615.

4 Kolb MS, Horme ML, Martz R. Dantrolene in human malignant hyperthermia. A multicenter study. Anesthesiology 1982; 56: 254-62.

5 Onding $H$, Hedengran AM, Skovgaard LT. Evaluation of 119 anaesthetics received after investigation for susceptibility to malignant hyperthermia. Acta Anaesthesiol Scand 1991; 35: 711-6.

6 Ording $H$, Nielsen VG. Atracurium and its antagonism by neostigmine (plus glycopyrrolate) in patients susceptible to malignant hyperthermia. Br J Anaesth 1986; 58: 1001-4.

7 Larach $M G$, Rosenberg $H$, Larach DR, Broennle AM.
Prediction of malignant hyperthermia susceptibility by clinical signs. Anesthesiology 1987; 66: 547-50.

8 Ording $H$, Fonsmark $L$. Use of vecuronium and doxapram in patients susceptible to malignant hyperthermia. $\mathrm{Br}$ J Anaesth 1988; 60: 445-9.

9 Gielen $M$, Viering $W$. 3-in-1 lumbar plexus block for muscle biopsy in malignant hyperthermia patients. Amide local anaesthetics may be used safely. Acta Anaesthesiol Scand 1986; 30: 581-3.

10 Berkowitz $A$, Rosenberg $H$. Femoral block with mepivacaine for muscle biopsy in malignant hyperthermia patients. Anesthesiology 1985; 62: 651-2.

11 Britt BA. Malignant hyperthermia - a review. In: Schonbaum E, Lomax P (Eds.). Thermoregulation: Pathology, Pharmacology and Therapy. New York: Pergamon Press, Inc. 1991: 179-292.

12 Larach $M G$, Localio AR, Allen GC, et al. A clinical grading scale to predict malignant hyperthermia susceptibility. Anesthesiology 1994; 80: 771-9.

13 Zar JH. Biostatistical Analysis, 2nd ed. Englewood Cliffs: Prentice-Hall, Inc., 1984: 378-9.

14 Hanley $J A$, Lippman-Hand $A$. If nothing goes wrong, is everything all right? Interpreting zero numerators. JAMA 1983; 249: 1743-5.

15 Grinberg $R$, Edelist G, Gordon A. Postoperative malignant hyperthermia episodes in patients who received "safe" anaesthetics. Can Anaesth Soc J 1983; 30: 273-6.

16 Larach $M G$ for the North American Malignant Hyperthermia Group. Standardization of the caffeine halothane muscle contracture test. Anesth Analg 1989; 69: 511-5.

17 Britt $B A$. Elective and emergency treatment of malignant hyperthermic susceptible patients. In: Nalda F, Gottmann S, Khambatta HJ (Eds.). Malignant Hyperthermia: Current Concepts. International Course, Barcelona, Spain, September 15-17, 1988. Bad Homburg: Normed Verlag, 1989; 108-32.

18 Gronert GA, Milde $J H$. Variations in onset of porcine malignant hyperthermia. Anesth Analg 1981; 60: 499-503. 